\title{
Geomatics and virtual tourism
}

\author{
Valeria Minucciani, ${ }^{1}$ Gabriele Garnero² \\ ${ }^{1}$ DAD, Dipartimento di Architettura e Design, Politecnico di Torino, Torino, Italy; \\ ${ }^{2}$ DIST, Dipartimento Interateneo di Scienze, Progetto e Politiche del Territorio, Università e \\ Politecnico di Torino, Torino, Italy
}

\begin{abstract}
The most recent technological revolution, concerning web and "ICT", not only changed individual and collective behaviors, but also allowed experiences no possible before: a real time communication, regardless of the distances; an extended access to disjointed data and sources; the shift in different realities - missing or entirely imaginary. Nowadays, we can think about a new concept of museum, much more inclusive than "objects container": now the museum involves entire countries, entire ecosystems, entire regions. We can speak of "museum outside of the museum", to extend museum "storytelling" to a regional scale, beyond the walls of the traditional museum. On a regional scale experiments entirely convincing have not yet been carried out, but from this point of view cultural lands can be visited as great open air museums, to find objects, artworks or signs: the whole land is a "collection" to be preserved, to be presented and to be interpreted. Thus the visit allows to elicit outstanding objects, to read into landscapes with different filters. Both the physical and virtual visit seem to be a "tour" (Minucciani and Garnero, 2013). To create a virtual tourism prototypal station, we need several and unconventional geometrical data (shared geographic databases, DTMs, digital orthoimages and angle shots, modeling with spherical cameras, ...), thematic data (related to cultural content) and no conventional input units to move and to observe how and where the observer prefers. Authors report here their experience to carry out a prototypal station, able to relate geomatics references to cultural content and to offer a whole
\end{abstract}

Correspondence: Gabriele Garnero, DIST, Università e Politecnico di Torino Via Leonardo da Vinci, 44, 10095 Grugliasco (T0), Italy.

Tel. +39.011.670.5518 - Fax: +39.011.670.5516.

E-mail: gabriele.garnero@unito.it

Contributions: the authors contributed equally.

Conflict of interest: the authors declare no potential conflict of interests.

Funding: no source of funding

Key words: museography, virtual tourism, geomatics and shared databases, human computer interaction, social inclusion.

(C) Copyright V. Minucciani and G. Garnero, 2013

Licensee PAGEPress, Italy

Journal of Agricultural Engineering 2013; XLIV(s2):e100

doi:10.4081/jae.2013.s2.e100

This article is distributed under the terms of the Creative Commons Attribution Noncommercial License (by-nc 3.0) which permits any noncommercial use, distribution, and reproduction in any medium, provided the orig- experience, involving users also from the sensory point of view.

That's nowadays a specific purpose of new technologies applied to cultural heritage.

\section{ICT and virtual tours}

The concept of virtual museum is by now established, multi-faceted and so widespread that it is now inflated: but a shared definition isn't given yet, and it indicates the possibility of access to the historical, artistic and cultural heritage through the network, sometimes replacing sometimes integrating the real experience of visit.

Then we have "virtual museums" that simply are "catalogs" on line, but we have also cases in which, with more or less interaction, we can perform via video real visits (selecting paths, objects, information). The static nature of these experiences is often the weakest point, despite considerable progress (Caraceni 2012; Minucciani, 2009a; Minucciani 2009b; Antinucci, 2007). In general, they interpret "virtual" as "simulation" (on the screen) of a real experience.

This "replacement" (which anyway provides immediate availability and accessibility everywhere - sometimes more than in the real situation) nevertheless pays a price, that's - above all - disorientation and barrier effect of the screen.

Even very recent projects (e.g. Google Maps service "Google Business Photos": after Spain, Denmark and Sweden it's now running available also for Italy - see the "Museo dell'Automobile" case, in Turin), providing an access to interiors thank several $360^{\circ}$ pictures, don't completely overcome this hurdle. Fundamentally, they hat replicate indoor the Street View solution.

Likewise if we mean "virtual tourism" reductively as "access to information" related to a place, it seems to be aseptic and far, via video. We cannot define it as "tourism", but rather as "cultural or touristic information".

The loss of the viewer's corporeality creates alienation and separation, thus we need a kind of "alter ego" to fill this gap. So, if we attribute to the term "virtual" its scientific meaning, i.e. simulation of reality (and consequently simulation of experience), new scenarios open (Vince, 2004): not only the computer version of a real place, but also a place that does not exist - or that no longer exists...

Some experiments have enhanced museums by "virtual guides", i.e. synthetic characters that can interact with visitors in a more or less advanced way (Minucciani, 2009a). In other cases, they attempted to give back a "physical", bodily dimension to the virtual tour: in Italy one of the pilot cases goes back to 1994, and it concerned the virtual reconstruction of Nefertari tomb (Antinucci, 2007) ("Nefertari: Luce d'Egitto", temporary exhibition in Rome, Palazzo Rispoli, 1994).

But in this field there have been many other experiments, (in particular, see V-MusT.net NoE experiments during 2012-2013 period (www.v-must.net), more or less immersive, someone scientifically rigorous, someone similar to videogame tout court, someone very poor 
from the cultural point of view (Minucciani, 2009a; Minucciani, 2009b). They're studying solutions - using geo-caching, geolocation in interior (still a bit problematic) - that offer really educative "games" involving the entire web community: in this regard it should be noted that the Web 2.0 advent has given further impetus to virtual experiences, enriching the cultural impact with socialization and sharing (See Tate Gallery case (www.tate.org.uk/britain/exhibitions/ howweare/) or Brooklyn Museum of NY (Click! A crowed-curated exhibition: www.brooklynmuseum.org/exhibitions/click/)), (Proctor, 2010).

Furthermore, the new concept of museum (Poulot, 2005), much more inclusive than simple "objects container", enclosed by walls and clearly divided between "inside" and "outside. Now the museum could involve entire countries, entire ecosystems, entire regions. We can speak of "museum outside of the museum" (Minucciani, 2005), that extends museum "storytelling" to a regional scale, beyond the walls of the traditional institution. On a regional scale experiments entirely convincing have not yet been carried out, but from this point of view the cultural lands can be visited as great open air museums, with transversal or theme paths, to find objects, artworks or signs: the whole land is a "collection" to be preserved, to be presented and to be interpreted. Thus the visit allows to elicit outstanding objects, to read into landscapes with different filters. Both the physical and virtual visit seem to be a "tour".

In fact, the new concept of "virtual tourism" is very similar to "virtual museum", but it's more inclusive (Wang, 2011a; Gerosa, 2011; Gärtner at al., 2010; Gretzel et al., 2010; Minucciani, 2009a; Minucciani, 2009b; Hyun et al., 2009; Cheong, 1995; Williams e Hobson, 1995).

Its own meaning is still not universally shared, anyway it originates from the advent of new technologies in the tourism industry: not only regarding new channels of information and purchase, but also the "virtual tours", exploring synthetic worlds (sometimes encroaching on videogame) or the real world. Nowadays the attention is focusing on the second one. Often the "virtual tourism" is defined as "stationary tourism", but they're trying to overcome this feature also because territory perception and his understanding are more complex than a remote visit to museum.

Actually, we could define "virtual tourism" two different cases: a virtual trip in a virtual site (that's a model, mirroring the real world or not) and a real trip (that's powered by another reality - the augmented one). Of course, there is a lot of intermediate options, and we have to take account of specific purposes and different goals (commercial, cultural, entertaining...). But we would like to focus on solutions that don't resort to models and virtual worlds, but instead aim to face to real environment.

About database construction, in addition to traditional, cartographic bases are now achievable different information sources (orthoimagery, digital models produced by photogrammetric correlation to LiDAR takes ...).

Current technology is mature to support specifically these applications with products as UAV shootings (made with extremely manageable and low cost aircrafts, operating with a high degree of automation to realize updated shooting at sustainable costs); reliefs by single "session" (with equipped aircrafts and high-performance vehicles, to acquire information components - photographic - and metric components - LiDAR); use of spherical cameras, able to acquire "views" to be freely visited by user (Figure 1).

\section{Real sites, virtual tourism}

Focusing on tourism in real sites, they're attempting to expand the perception and knowledge modes, also thank to open databases more and more extensive.

We can acquire information in increasingly articulated ways, in order to rejoin virtual world and real experience.

For a long time the Authors are interested in this field (Minucciani, 2012; Vaudetti et al., 2012; Minucciani, 2009a; Minucciani, 2005). They believe that communication of cultural heritage has yet to fully benefit from the new technologies chances, not only in Italy (where the matter is particularly urgent and strategic, although their country isn't an emerging model about ICT exploitation for Cultural Heritage). In addition, they trust in a cultural and social mission of virtual tourism: it shouldn't not only enhance already known and possible functions (increasing the commerce and information occasions), but it should also broaden avails to situations and categories of people who have so far been excluded, in different ways.

They are convinced that the time savings should not sacrifice the awareness of real parameters (distances, differences) and that the socalled edutainment shouldn't be a simple compromise between different needs, but rather a richer opportunity. Thus their interest is addressed to technologies able to tie virtual visit and real site. Furthermore, they want to pay more attention to "visitor's body", i.e. his physical involvement, in virtual experiences.

Many projects facing this issue are already been carried out: from simple "virtual books or tables" to particular experiments as PointAt, (These solutions are interactive installations, the first one to consult documents, while PointAt allows to learn more about a digital version of an artwork, just pointing the finger on details - that's a very instinctive gesture (Museo del Palazzo Medici Riccardi, Firenze, 2003)), Museum Wearable, (This small, lightweight computer, in a carrying backpack, was connected to a body motion sensor and to augmented reality glasses and headphones, in order to support and enhance the museum visit (temporary exhibition "Robots and Beyond", MIT Museum, Boston 2000)), Cave, (An enterely virtual, immersive environment you can visit thank stereoscopic glasses and special "mouses" (e.g. Kivotos system, Foundation of Hellenic World, Athens 1999)), haptic interfaces, holograms and so on. In these cases, anyway, virtual real-

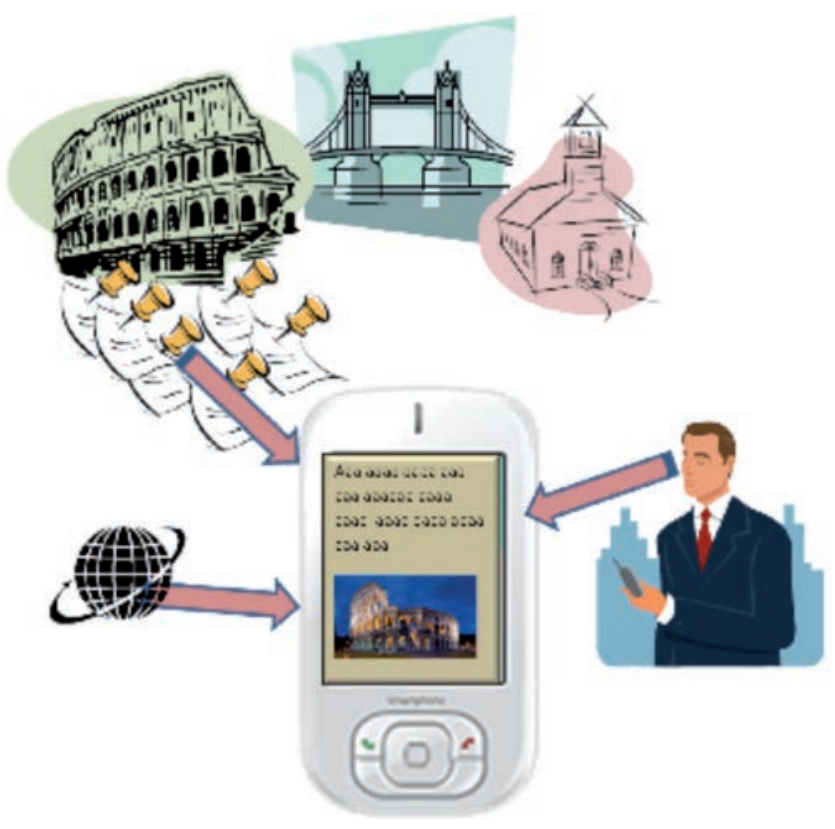

Figure 1. Multiple access to information. 
ity integrates real environment - through 3D models and simulations.

The Authors have just developed a project aiming to explore the opposite situation, integrating the virtual environment by real elements.

About this issue, an interesting project has already been carried out: the virtual "Trans Siberian Railway". Thanks to a simple video camera system, it offers the real sights from the train window along the 9000 $\mathrm{km}$ travel. The website also features images of small cities crossed, as well as tourist information, related to Google Maps (http://www.google. $\mathrm{ru} / \mathrm{int} \mathrm{l} / \mathrm{ru} / \mathrm{landing} / \mathrm{transsib} / \mathrm{en}$.html. The project was originated from a collaboration between Google Maps and Russian Railways). However, they miss an element that Authors consider crucial: the real interaction with physical movement of the user. Although friendly and shared, a map is an abstraction and cuts immersive effect. All information access should be strictly related with a real sight, and originated from it: interaction interface is crucial.

Thus, as the objective is to merge physical and virtual reality, involving the body motion, the challenge is interesting because they want to present the real views, without 3D models. Another issue becomes crucial: the increase of data sharing, e.g. data related to systems as primarily Google Earth, Google Maps and Street View - now in common use. They already can provide, completely free, real images of the sites on global scale. Their content are by now integrated tools, namely repository of territorial data that we can integrate and share.

Recently, another opportunity has been jointed: integration of local and remote databases of images, and implementation in GIS systems (Ferrante and Garnero, 2013, Pirotti et al., 2011).

Virtual Earth and Google Earth use a cartographic representation system not yet implemented - in Italy - in other applications (http:/www.google.ru/int//ru/landing/transsib/en.html. The project was originated from a collaboration between Google Maps and Russian Railways). Particularly interesting for our purpose are the geo-referenced images of Google Street View, implemented within Google Maps and Google Earth that provides panoramic views of $360^{\circ}$ horizontally and $290^{\circ}$ vertically along the streets (at a minimum distance of 10-20 meters apart). It was introduced in May 2007, and it runs in Italy since October 2008: Street View allows users to view portions of cities around the world at ground level, by placing on the map a little orange man.

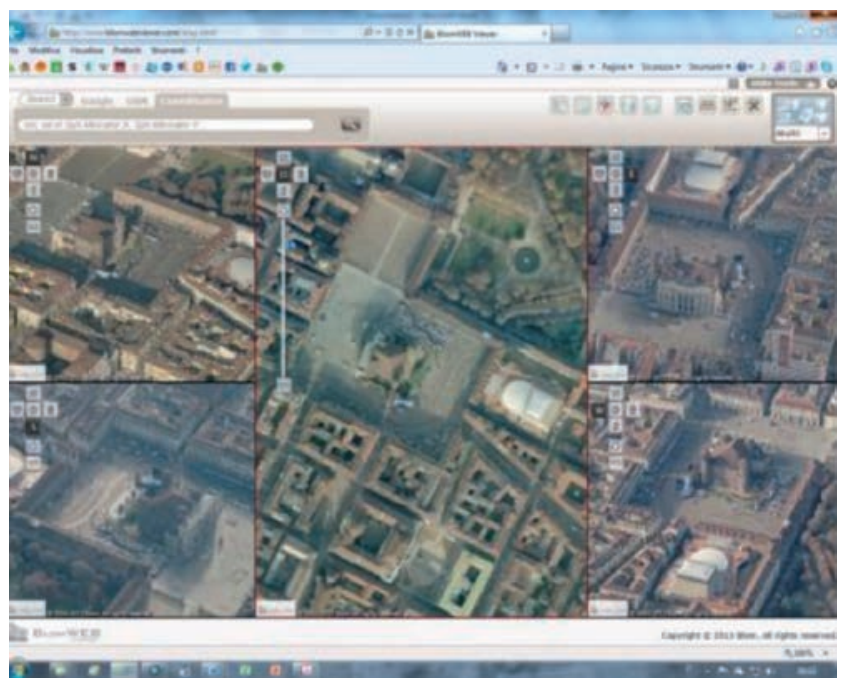

Figure 2. Nadir sight and 4 angle shots of Turin - area of "piazza Castello".
Google Street View uses special cameras (the Dodeca 2360, with 11 goals and produced by the Canadian company Immersive Media) located on the roof of cars or equipped bikes. The service is now extended to main roads and urban streets of large and small centers, across all Italian regions (The updated coverage is available online at http://www.google.com/help/maps/streetview/learn/where-is-streetview.html).

The images quality is satisfying, although they may perceive the "junctions" among consecutive shots.

Furthermore, there are other databases of images that can integrate "real" views (i.e. at eye level), to offer to users a complete description of sites. First, the digital orthoimages (high definition) and angle shots (able to acquire buildings facades). The industrial solutions (Pictometry ${ }^{\circledR}$, Midas ${ }^{\circledR}$ of Track'air, iOne ${ }^{\circledR}$ Visual lntelligence,...) use systems of cameras, connected to each other and assembled on a single support (Pictometry and Midas systems have 5 cameras: 4 are installed with an inclination of $40-45^{\circ}$ from the vertical and according to the four directions of view perpendicular to each other (forward, backward, left and right); the fifth camera takes from the zenith. Thus different frames share the same take instant).

In fact, in order to know and document the buildings appearance without performing measurements, less expensive systems are available: e.g. drones (UAV, Unmanned Aerial Vehicle) with photographic equipment. The APR (Aircraft Pilot in Remote) will be able to perform low altitude shots everywhere.

Finally, is now possible to create $3 D$ City Models, namely consultation environments where the buildings are geometrically modeled and then "dressed" with their facades. 3D City Models are one of geomatic products available for a long time, but only the recent improvements in the autocorrelation techniques may allow automatic generation processes, therefore openings to more generalized use.

All of these activities are nowadays made possible by the generalized availability of digital terrain models (DTM). They're got thank to photogrammetric autocorrelation techniques, cartographic data and - as it often happens by now - specific LiDAR shootings (Pelagatti et al., year not specified; INSPIRE, 2007).

Digital Terrain Models (DTM) are a resource in environment and land related applications. They can be employed in several way in order to deepen the comprehension of an area investigated by extracting morphometric parameters or to perform complex analyzes on the DTM alone or by combining it with other data sources with modeling purposes (Godone and Garnero, 2013; Pirotti et al., 2012; Chiabrando et al.,. 2011) (Figure 2).

A further contribution comes from the increasing standardization of cartographic production, advocated by the INSPIRE Directive and recently inserted in the current Italian regulations (Garnero et al., 2013; Ferrante and Garnero, 2013, INSPIRE, 2007).

\section{State-of-the-art: the case study of Turin}

Other, different databases can be related: information about history, architecture, cultural heritage. An interesting case study is MuseoTorino.

Launched during the celebrations for the $150^{\text {th }}$ Anniversary of Italian Unification, it's the new on line museum of Turin and it aims to collect, preserve and communicate information about cultural, historical and artistic heritage of the city, and more. The website (www.museotorino.it) is conceived and structured as a museum, where you can find information on places, people, events, itineraries (thank a browsable map of the contemporary city). Each item has a brief label and a file containing notes and information. The most inter- 
esting feature is the use of the latest platforms and technologies based on the Web 3.0 (semantic web) and Linked Open Data philosophy. Museum staff has been working on the website creation and data collection since 2009, and they have produced so far more than 15.300 files on places, events, themes and characters. Each file has been stored in a new generation database, a GraphDB providing excellent performances in data management.

This database is "museum catalogue", which can be consulted online, open to free searches. You can also move across the contemporary city, through a Google Maps application, and travel through time by visiting the permanent historical exhibition on the history of the city. MuseoTorino aims to involve the largest possible number of people, by sharing their knowledge and memories, suggesting ideas and projects. Icom Italia has awarded to MuseoTorino the prize Information Communication Technology (in occasion of Premio Icom Italia - Musei dell'anno 2011).

Thus, if the physical environment can be re-composed, instead of modeled, and if data and information can be collected and related, the visitor will be able to perform a "tour" without traveling. But his experience will be really "immersive" only if his motion and his perception of physical environment can be preserved.

So he will have several tools to move, literally, and to observe how and where he prefer (as if he were walking, for instance, but also turning his eyes or his head), namely natural ways with which he normally explores the world.

Suitable I/0 peripherals will ensure the correspondence between the physical motion of visitors and views (and a crucial requirement will be the level of immersion of output).

Furthermore, transposition of user' real motion along a trajectory, identified on Google Maps, will be put in relation in real-time with street view images. Several markers on these will allow to access (even through queries in natural language) not only to tourist information but also to cultural ones, detailed and specific, that will catch from different databases. Travel will be featured by shots specially made, in order to access also to particular interiors.

\section{A prototypal station}

Starting from aforesaid notes, the Authors believe users can really appreciate und understand the land features, with distances, relations, proportions and morphologies (i.e. the territories as "systems"). Among the requirements of a "real" tour, there is the free motion in places and the "guides" support. The new functions and services of augmented reality, in addition to unstoppable spread of smartphones (which nevertheless don't break the barrier effect of display), still require a cultural, strategic reflection.

The project therefore intends to explore a tour simulation with three basic features:

it offers to the "tourist" a real and immersive vision of what he would see across the places he's visiting, without turning to city models or synthetic worlds;

it brings together the virtual displacement on sites with a physical motion really made by the "tourist";

it uses shared databases.

The final prototype (replicable for different contexts - in urban environment and in extra-urban context - and for different situations of use) will allow to visit remote sites, without turning to traditional station in front of a monitor, but recovering movement and free choice of timing and sequences.

The virtual tourist would thus have the opportunity to visit any place, stopping when and how he wants.
The experience will provide most of the functions available for real tourism, improving them: among these, virtual tourists will be able can make stops, get into some interiors and benefit of observation points that are not possible in physical reality, but easily achievable in virtual way (elevations of points of view, spherical shooting etc..).

At last, there are different uses of databases: cloud systems availability and adequate, technological infrastructure allow creation of data bases adaptable to different needs, for scholars, conservation institutions, or simple curious and tourists.

Just the "virtual tourism" is the most attractive form to consult and use such information, because the observer-visitor, according to our project, can access specialized information in intuitive way, thank to navigation tools as described, maybe with virtual assistants and so on.

Of course, such information bases could be available also to users physically visiting real places, thank to positioning instruments (GNSS, gyroscope, compass, ...) already provided on smartphones and tablets Real tourists will able to access to same information body than virtual one, and to navigate by using the information architectures as geometric and thematic index, data retriving, metadating repertoire ....

Furthermore, at even larger scale, they will enter into the building / museum: dedicated systems will recreate a reference system (radio apparatus as GNSS systems emulators, objects identifications through QRcode, and so on) to enable real user to automatically synchronize, from its location, to available data bases.

Interaction should be as natural as possible, using also natural language and virtual assistants.

The project encompasses several disciplinary cores: museography (that's exhibition strategy and communication of cultural heritage, complemented by historical and technical disciplines); geomatics and image processing (connection between the visitor's motion, the geo and cartographic reference and related databases); virtuality (and web 2.0.), ontologies (and web 3.0); tourism sociology and marketing (implementation of investigation/verification techniques, and their transposition to the virtual tourism) (Figure 3).

\section{Conclusions}

The matter the Authors wish point out, in conclusion, relates to the use of technologies and databases now widely available.

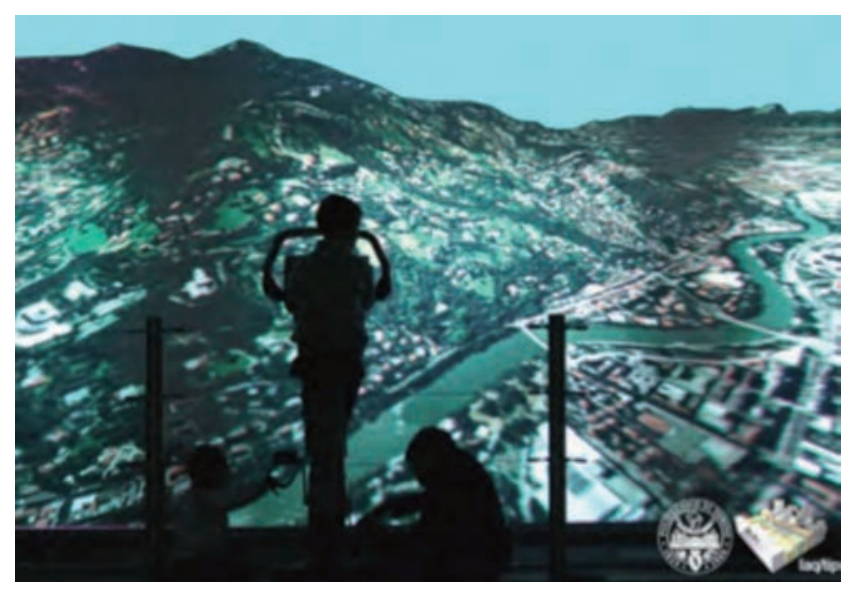

Figure 3. Immersive and interactive virtual reality, at LAQ (High Quality Laboratory) “Auditorium”, Politecnico di Torino. 
In fact, in addition to the scientific and experimental contents in itself, from their use can arise important effects for people.

Indeed it concerns not only economic and commercial business (even if the creation of new jobs and new employment sectors is undoubtedly important). Let's rather consider the social importance of a tourism solution that does not exclude whole, weak segments of population, due to income, age or disability.

In addition to effects of social inclusion (which is a main goal of European Strategy for 2020) should also be underlined the opportunity for a greater access to culture, that's a primary factor of human development and progress.

The territorial information systems leave "technical" fields and gain application contexts related to large public. For this reason, transversal use is crucial: we don't need "new knowledge bases", but to integrate them and provide interpretations (ontologies; network systems; systems person-based; systems on geographic key; various access systems, mutually integrated ...).

Also "closeness" is, in the most recent project, a crucial key to access information. In this field, due to great amount of interrelated information, and to worldwide spread, the Wikipedia project "Nearby" has really an excellent chance (http://blog.wikimedia.org/2013/05/29/wikipedianearby-beta/) (Figure 4).

The information of the largest free encyclopedia in the world will be connected with their geographical reference, so tourists or professional operators will able to browse starting from their real location and then accessing related information. "Nearby" application is already active.

But a true, "intelligent access" has to provide to you information you need, or tailored for you: nowadays, thank to information available e.g. on social networks, particular interests of any visitor can be saved and considered. Not only "where you are" is important, but also "who and how you are", because in the information sea you should find what you are really interested to know. Of course, this goal requires a great work on ontologies that have to cross with "social" data, very heterogeneous: each user has the right to receive "his ownr" information output.

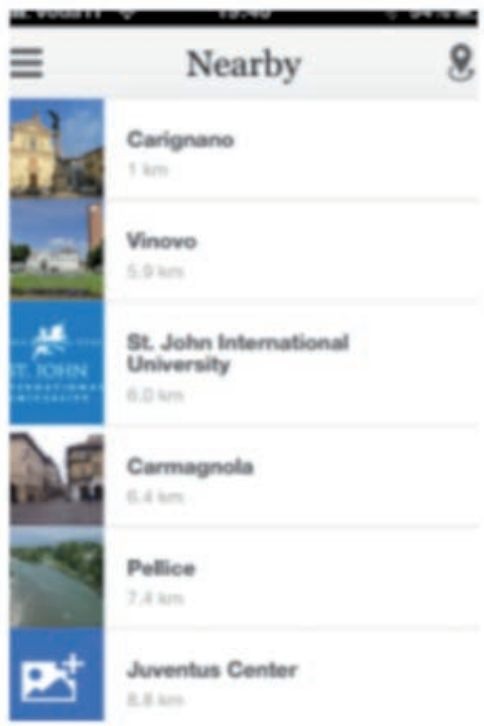

Figure 4. The Nearby feature on iPhone device.

\section{References}

Agarwal, J., Sharma, N., Kumar, P., Parshav, V., Srivastava, A., Goudar, R.H.: Intelligent search in E-Tourism services using Recommendation System: Perfect guide for tourist (2013) 7th International Conference on Intelligent Systems and Control, ISCO 2013, art. no. 6481190, pp. 410-415.

Antinucci, F.: Musei virtuali: come non fare innovazione tecnologica (2007), Roma-Bari Laterza

Barabé, A.: Evaluation of virtual learning environments : Analysis of an experimental activity related to training in sustainable tourism [Évaluation des environnements d'apprentissage virtuels : Analyse d'une expérimentation reliée à la formation en tourisme durable ] (2003) Loisir et Societe, 26 (1), pp. 211-233+9.

Caraceni, S.: Musei virtuali-Augmented heritage. Evoluzioni e classificazione delle tipologie di virtualità in alcuni case histories, (2012), Rimini Guaraldi

Chase-Levenson, A.: Annihilating time and space: Eclecticism and virtual tourism at the Sydenham Crystal Palace (2012) NineteenthCentury Contexts, 34 (5), pp. 461-475.

Cheong, R.: The virtual threat to travel and tourism (1995) Tourism Management, 16 (6), pp. 417-422.

Chiabrando, R.; Fabrizio, E.; Garnero, G.: On the applicability of the visual impact assessment OAISPP tool to photovoltaic plants, Renewable and Sustainable Energy Reviews (ISSN:1364-0321), pp. 845- 850, Vol. 15 (2011)

Cozzi, P.: Turismo e Web. Marketing e comunicazione tra mondo reale e virtuale, Milano, Franco Angeli (2010)

Davenport, E.: Localisation, globalisation and SMEs in European tourism: The 'virtual enterprise' model of intervention (2000) Proceedings of the ASIS Annual Meeting, 37, pp. 309-318.

Dong, H.: Review on the websites and virtual tourism of World Heritage sites in China (2010) 2nd International Conference on Information Science and Engineering, ICISE2010 - Proceedings, art. no. 5691830, pp. 6112-6114.

Ferrante, F.; Garnero, G.: Tecnologie e dati spaziali per una moderna governance del territorio. Strumenti a supporto della riforma del Catasto (Technologies and spatial data for modern land governance. Tools to support the cadastral reform.), Territorio Italia Governo del Territorio, Catasto, Mercato immobiliare, n. 01/2013, p. 9-26 (Italian and English version)

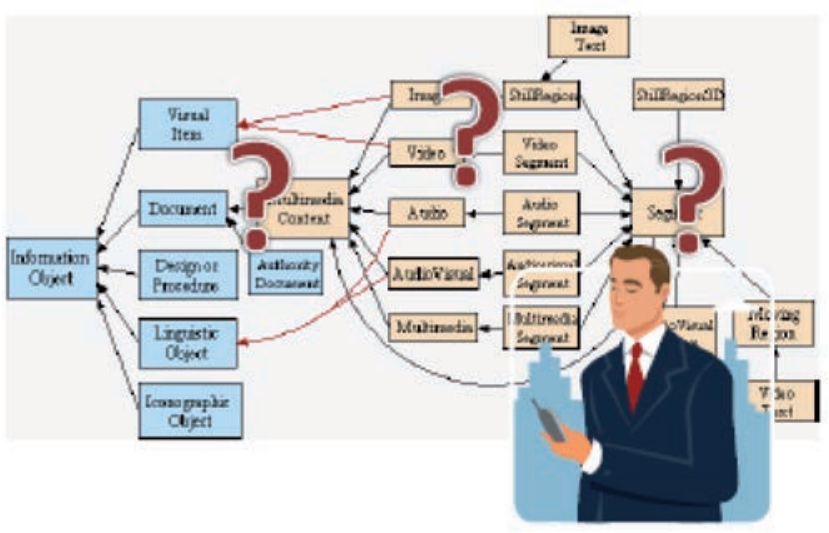

Figure 5. Ontologic interrogation of geographic and thematic DB. 
Gale, T.: Urban beaches, virtual worlds and 'the end of tourism' (2009) Mobilities, 4 (1), pp. 119-138.

Garnero, G.; Corrias, A.; Manigas, L.; Zedda, S.V.: VGI, Augmented Reality and Smart Web Application: Projects of Development in the Territory of the Sardinia Region, in B. Murgante et al. (Eds.): ICCSA 2013, Part IV, LNCS 7974, pp. 77—92. Springer, Heidelberg (2013)

Gärtner, M., Seidel, I., Froschauer, J., Berger, H.: The formation of virtual organizations by means of electronic institutions in a $3 D e$ Tourism environment (2010) Information Sciences, 180 (17), pp. 3157-3169.

Germann Molz J.; Gibson S.: Mobilizing Hospitality, Farnham, Ashgate (2007)

Gerosa, M.; Milano, R.: Viaggi in rete. Dal nuovo marketing turistico ai viaggi nei mondi virtuali (2011), Milano FrancoAngeli

Godone, D.; Garnero G.: The role of morphometric parameters in Digital Terrain Models interpolation accuracy: a case study, European Journal of Remote Sensing, (ISSN:2279-7254) 46: 198-214 [doi: 10.5721/EuJRS20134611] (2013)

Granieri G.; Perri G.: Linguaggi digitali per il turismo, Milano, Apogeo (2009)

Gretzel U.; Law R.; Fuchs M.: Information and Communication Technologies in Tourism 2010, Wien-New York, Springer (2010)

Hashim, K.H.B.: Jusof, M.J.B., Spherical high dynamic range virtual reality for virtual tourism: Kellie's Castle, Malaysia (2010) 2010 16th International Conference on Virtual Systems and Multimedia, VSMM 2010, art. no. 5665945, pp. 297-300.

Hernández, L.A., Taibo, J., Seoane, A.J.: Immersive video for virtual tourism (2001) Proceedings of SPIE - The International Society for Optical Engineering, 4520, pp. 63-73.

Hopeniene, R., Railiene, G., Kazlauskiene, E.: Potential of virtual organizing of tourism business system actors [Turizmo verslo sistemos dalyviu\{ogonek\} virtualaus organizavimosi potencialas] (2009) Engineering Economics, 3 (63), pp. 75-85.

Hsu, C.: The feasibility of Augmented Reality on virtual tourism website (2011) Proceedings - 4th International Conference on Ubi-Media Computing, U-Media 2011, art. no. 5992081, pp. 253-256.

$\mathrm{Hu}, \mathrm{Z}$. , Cao, Z., Shi, J.: Research of interactive product design for virtual tourism (2012) Lecture Notes in Electrical Engineering, 140 LNEE, pp. 411-416

Hyun, M.Y., Lee, S., Hu, C.: Mobile-mediated virtual experience in tourism: Concept, typology and applications (2009) Journal of Vacation Marketing, 15 (2), pp. 149-164

INSPIRE Directive Of the European Parliament and of the Council of 14 March 2007 establishing an Infrastructure for Spatial Information in the European Community - Directive 2007/2/EC (2007)

Kapp K. M.: The Gamification of Learning and Instruction: Game-based Methods and Strategies for Training and Education. John Wiley \& Sons (2012)

Kim, L.C., Lam, T.K., Talib, A.Z.: Acoustical heritage for virtual tourism on mobile platform (2011) Proceeding of the International Conference on e-Education Entertainment and e-Management, ICEEE 2011, art. no. 6137804, pp. 273-276.

Kuntarto, G.P., Gunawan, D.: Dwipa search engine: When E-tourism meets the semantic web (2012) 2012 International Conference on
Advanced Computer Science and Information Systems, ICACSIS 2012 - Proceedings, art. no. 6468741, pp. 155-160.

Maymand, M.M., Farsijani, H., Tahery Moosavi, S.S.: Investigation of the key success factors in virtual tourism, (2012) Indian Journal of Science and Technology, 5 (7), pp. 3073-3080.

Minucciani, V.; Garnero, G.: Available and Implementable Technologies for Virtual Tourism: A Prototypal Station Project, in B. Murgante et al. (Eds.): ICCSA 2013, Part IV, LNCS 7974, pp. 193-204. Springer, Heidelberg (2013)

Minucciani, V.: Pensare il museo. Dai fondamenti teorici agli strumenti tecnici. p. 1-199, Rivoli (T0):CET - Casa Editrice Torinese, ISBN: 9788896470060 (2012)

Minucciani, V.: Musei e tecnologie virtuali, Tafter Journal, ISSN: 1974 563X (2009a)

Minucciani, V.: Artifici tecnologici al servizio della narrazione archeologica. In: Celada, G.; Gentilini, C.; Martinelli, C.: Palestrina. La città $e$ il tempio. p. 199-211, Maggioli, ISBN: 9788838743382 (2009b)

Minucciani, V.: Il museo fuori dal museo, ISBN 9788882230739, Milano, Lybra Immagine (2005)

Pelagatti et al.: SpatialDBgroup Weblink to a page about IDT http://spatialdbgroup.polimi.it/visione/ (year not specified)

Pirotti, F., Grigolato, S., Lingua, E., Sitzia, T., Tarolli, P.: Laser scanner applications in forest and environmental sciences, Italian Journal of Remote Sensing / Rivista Italiana di Telerilevamento, 44 (1), pp. 109-123 (2012)

Pirotti, F., Guarnieri, A., Vettore, A.: Collaborative Web-GIS Design: A Case Study for Road Risk Analysis and Monitoring, (2011) Transactions in GIS, 15 (2), pp. 213-226.

Poulot, D.: Musée et muséologie (2005), Paris La Découverte

Proctor, N.: Digital Museums as Platform, Curator as Champion, in the Age of Social Media, Curator (2010)

Roberta, K.V., Wisudawati, L.M., Razi, M., Agushinta R., D.:Web based virtual agent for tourism guide in Indonesia (2011) Communications in Computer and Information Science, 191 CCIS (PART 2), pp. 146-153.

Vaudetti, M.; Minucciani, V.; Canepa, S. (a cura di): The Archaeological Musealization Multidisciplinary Intervention in Archaeological Sites for the Conservation, Communication and Culture, p. 9-280, Torino, Allemandi \& C., ISBN: 9788842221203 (2012)

Vince, J.A.: Introduction to Virtual Reality (2004), London Berlin Heidelberg, Springer-Verlag

Wang, F.-X.: Design and implementation of Hainan tourism spots virtual reality system (2011a) Key Engineering Materials, 474-476, pp. 2217-2220

Wang, C.: Application of virtual reality technology in digital tourism (2011b) Proceedings - 3rd International Conference on Multimedia Information Networking and Security, MINES 2011, art. no. 6103831 , pp. 537-541.

Williams, P., Hobson, J.P.: Virtual reality and tourism: fact or fantasy? (1995) Tourism Management, 16 (6), pp. 423-427.

Zhang, Y., Zhang, X.: An integrated application of tourism planning based on virtual reality technology and indicator assessment (2012) Lecture Notes in Electrical Engineering, 107 LNEE, pp. 1435-1442. 